"This is an Author's Accepted Manuscript of the article Liesbeth Van Parys \& Ludo Struyven (2012): Liesbeth Van Parys \& Ludo Struyven (2013) Withdrawal from the public employment service by young unemployed: a matter of non-take-up or of non-compliance? How non-profit social work initiatives may inspire public services, European Journal of Social Work, 16:4, 451-469 [online since 17 September 2012] [copyright Taylor \& Francis], available online at: http://www.tandfonline.com/10.1080/13691457.2012.724387 "

\title{
Withdrawal from the public employment service by young unemployed: a matter of non-take-up or of non-compliance? How nonprofit social work initiatives may inspire public services
}

Liesbeth Van Parys ${ }^{1} \&$ Ludo Struyven ${ }^{2}$

In their effort to increase labour market participation, several EU welfare states are currently confronted with the problem of an 'off-register NEET generation', i.e. a significant group of unemployed youngsters who do not register with the public employment service (PES) or withdraw early. Their behaviour is puzzling as they risk a penalty in the form of a reduction or a loss of benefits. Combining insights from non-compliance theory and non-take-up theory, this article argues that this withdrawal cannot be fully explained by the calculations of risks, costs and benefits that these youngsters make, nor by problematic attitudes. At least as important are the factors at the organisational level which prevent the youngsters from taking up their rights. An alternative activation approach based on private nonprofit social work practice, namely integrated guidance is proposed in order to improve participation in PES services. The findings are based on a study of nine pilots involving hard-to-reach young unemployed people in Belgium. A triangulation of quantitative and qualitative methods was used to collect and analyse the data.

\footnotetext{
${ }^{1}$ Correspondence to: Liesbeth Van Parys, Labour Market Research Group, HIVA-K.U.Leuven, Parkstraat 47 box 5300, 3000 Leuven, Belgium. Tel.: +32 163231 14; Email: liesbeth.vanparys@kuleuven.be ${ }^{2}$ Ludo Struyven, Labour Market Research Group, HIVA-K.U.Leuven, Leuven, Belgium.
} 
Keywords: Active labour market policy; Public employment service; NEET; Non-take-up; Non-compliance

\section{Introduction}

Since the 1990s, several EU welfare states have changed their employment policies so as to increase the labour market participation of their citizens. These changes take the form of a double individualisation strategy, aimed at enforcing both individual rights and responsibilities. Firstly, governments emphasise the personal responsibility of individuals to end their state of dependency by making the unemployment benefit conditional upon their cooperative behaviour - if necessary by use of sanctions (Handler, 2004). Secondly, service delivery has become less standardised so as to allow for trajectories to work tailormade/responsive to the diverse needs of the jobless individuals (van Berkel \& Valkenburg, 2007). While this activation strategy is backed by a political majority in an increasing number of countries, it is being questioned by several social science scholars. Pascual $(2009,65)$ identifies a tension between the conceptualisation of the individual as a self-governing subject capable of developing a personal project in line with own preferences and principles on the one hand and the coercive policy instruments (monitoring, sanctions) which reflect a distrust in citizens' motives on the other. In a similar line, other scholars point to the imbalance between the emphasis on the coercive side of activation (monitoring, sanctions) at the expense of investments in enabling, empowering services (e.g. Bonvin, 2008; Freedland \& King, 2005). Malmberg-Heimonen \& Vuori, 2005 show that such policy strategy may be counterproductive for enforced (in contrast to voluntary) participation in activation programmes is found to impair rather than improve the effect on self-efficacy of participants and to discourage rather than encourage.

Indeed, empirical signs of the limits of activation are becoming apparent, particularly among young unemployed people - who have been the test-case of these policies in several 
countries (Lindsay \& Mailand, 2004). Against this background, the first part of this article shows that several EU countries are confronted with the problem of a significant group of unemployed youngsters who do not engage with the public employment service (PES) or withdraw early, even though they risk a penalty in the form of a reduction, loss or postponement of benefits. Secondly, we present two theoretical traditions that attempt to account for this phenomenon, namely non-compliance and non-take-up theory. In a third part, these theoretical insights are confronted with the results of an evaluation study of nine pilot projects set up by the Flemish PES (VDAB) to tackle the problem of youngsters withdrawing from employment services. In these pilots, VDAB cooperated with private nonprofit social work initiatives experienced in working with the target group. The conclusions are presented and discussed in the final section.

\section{When Activation Reaches its Limits}

The last two decades have witnessed a trend towards individualisation in the field of social policy (e.g. care and health) and particularly with regard to employment policies in Western welfare states. A twofold trend can be observed, i.e. greater individualisation of responsibility and greater individualisation of services. More specifically, governments encourage individuals to take responsibility for their own situation by making unemployment benefits conditional on active participation through a system of monitoring and sanctions (Handler, 2004). In turn, governments themselves make the effort to tailor services and their delivery to the specific needs of each unemployed individual (van Berkel, 2007). This should be seen in the light of the increased heterogeneity of the unemployed as governments strive to 1) activate as many citizens as possible (including the harder-to-place and previously inactive groups); and 2) respond to the increasing requirements of employers on the demand side of the labour market (Gore, 2005). 
Thus, governments strive to strike a balance between full coverage (the EU's 'comprehensive approach') on the one hand and tailoring services to everyone's needs on the other. No doubt, this tension intensifies the three core dilemmas in welfare work (Hjörne et al., 2010): supply-demand, standardisation-responsiveness, and autonomy-control. As the number of clients increases, service demand (needs) starts to exceed supply (resources). While it is tempting to address this problem through greater standardisation, it is more useful to tailor services to the increasing diversity of needs. However, the increasing emphasis on monitoring and sanctions and on managerial accountability by the use of performance targets seems to limit front line officials' autonomy (discretion). Several authors (Freedland \& King, 2005; Bonvin, 2008) have warned of the danger of unequal treatment that may occur if front line officials are unable to invest sufficient time and effort in the support of each unemployed individual and in the collection of adequate information on the individual's efforts and capabilities.

Empirical evidence indeed indicates that not all unemployed people respond as intended to the activation policies implemented by the PES. In various European countries, each with different conditions for the provision of benefits and services, a group of jobless youngsters do not participate in the PES. They are labelled as problematic from the perspective of current activation policy which considers skills attainment and work experience as preconditions for societal integration in a 'knowledge driven economy' (Lawy, 2010). In the United Kingdom, this group - termed the 'off-register NEET' i.e. those not in education, employment or training and not claiming a Jobseeker's Allowance or other unemployment-related benefits was estimated to comprise about half a million 18-24 years old in 1997 (Bentley and Gurumurthy, 1999, p. 29; Furlong, 2006). The majority of these young people are either actively job seeking, caring for someone, or studying part time. Yet the reason for the NEETstatus of one out of five remains unclear. According to a study by Lakey et al. (2001), a part 
of the young unemployed with multiple barriers believe the New Deal programmes are a waste of time and that resources such as these do not meet their needs. In the Netherlands, only one in four NEETs was registered with the Dutch PES in 2007 (Algemene Rekenkamer, 2008, p. 43). While some of them are inactive due to a disability or care commitments, a vast group again is believed to have no particular reason for not looking for a job. For Belgium, finally, Van Hemel et al. (2009) estimate that annually about $13 \%$ of the young unemployed do not register at the regional PESs. Only a number of these young people are known by other public organisations such as the social assistance service or the National Institute for Sickness and Disability Insurance (RIZIV). Even though this share is rather low compared to the Netherlands, it is high taking into account that Belgian youngsters have a particular incentive to register with the PES, as school leavers need to register immediately to be eligible for a socalled 'waiting period allowance' later on. ${ }^{1}$

Thus, despite their - moderate or widespread - reforms in the provision of benefits and services reforms to promote activation, governments are confronted with a group of youngsters who do not engage with the PES even though they risk a penalty (benefit loss or reduction). The cited studies indicate that these youngsters are not necessarily deliberate 'noncompliers' but rather face a number of obstacles. Moreover, these European findings as well as those of Chen (2011) in Taiwan suggest that these obstacles do not only stem from individual factors but also from the quality and the organisation of the service delivery. However, so far the precise nature of these obstacles at the individual (micro) and the organisational (meso) level and their interaction remains unclear. This study contributes in several ways to the untangling of this phenomenon both theoretically and empirically. Firstly, we investigated who these youngsters are. Secondly, in order to fully grasp their behaviour, we confronted and combined the insights of non-compliance theory and non-take-up theory. Finally, this study addresses a gap in the literature on non-take-up. While previous studies so 
far focused on benefits (Van Oorschot, 1991; Minas, 2005), we applied the theory on the nontake-up of services.

\section{Theoretical Framework}

\section{Non-compliance}

Applying Gary Becker's (Becker \& Landes, 1974) work on the economics of crime to the case of unemployment insurance fraud, Burgess (1992) developed a model of noncompliance, identifying five factors affecting non-compliance. Firstly, non-compliance is determined by the probability of detection: the higher the likelihood that a lack of efforts to look for a job will be detected, the higher the level of compliance. Secondly, the larger the penalty for non-compliance, the more likely individuals will be to meet their obligations. Finally, compliance is more likely if the unemployed person can apply for jobs offering higher wages, takes a systematic rather than random approach to job searching, and has lower non-market opportunity costs (e.g. leisure).

However, it can be questioned whether deliberate non-compliance necessarily results from a risk calculation process. Dean's (2003, p. 449) study on activation in the UK shows that non-compliance may also occur because unemployed individuals with multiple problems feel treated with disrespect by the PES and prefer to sidestep official channels and to enter peripheral labour markets, i.e. a 'self-assertion strategy'. Marthinsen and Skjefstad (2011) in turn show that recognition by the social worker is a crucial factor for the enhancement of the self-confidence of receivers of income substitution participating in the Swedish Work and Competence programme. Furthermore, a study by Van Hemel and Struyven (2008) on persistent youth unemployment in Belgium indicates that young unemployed people often feel 'robbed by the system'. Particularly more vulnerable youngsters tend to anticipate less and 
hence to be sanctioned more often (Ibid.; Finn, 2003). Clearly, non-compliance theory does not allow us to explain all forms of non-participation.

\section{Non-take-up}

From the perspective of the non-take-up literature (van Oorschot, 1998; Hernanz et al., 2004), the fact that youngsters do not or no longer use the PES is considered as a problem of underconsumption of rights. However, in order to apply the model of non-take-up to our study on the non-participating young unemployed, a crucial difference to be taken into account is that the nature of the offer is different. While the existing literature focuses on the non-take-up of benefits, which are pecuniary and 'passive', our study is concerned with services, which are non-pecuniary and 'active', i.e. the unemployed are expected to participate in counselling, training and interviews. The crucial difference between benefits and services is that a benefit is granted once (and paid once or repeatedly) while the take-up of a service is often a longer process, entailing repeated interaction between the counsellor and the beneficiary. Therefore, the factors causing non-take-up of services can be expected to relate to more (diverse) aspects of the delivery process. Moreover, these factors will not necessarily be apparent at the start of the process.

The studies reviewed by Hernanz et al. (2004) consider non-take-up as the result of a cost benefit analysis by the individual. More precisely, the individual weighs up the value of the benefit/service against the costs of applying for it. Four types of costs are distinguished:

pecuniary costs (e.g. the cost of a stamp), information costs (i.e. the time and effort needed to gather and understand the information), administrative costs (i.e. the time and effort spent on the application procedure) and social and psychological costs (e.g. stigma).

van Oorschot (1998) questions whether non-take-up is (entirely) the result of a rational calculation by the individual. More precisely, before one can undertake a cost-benefit 
analysis, five thresholds need to be crossed: 1) one needs to be aware of the existence of the scheme; 2) one needs to perceive oneself as eligible; 3 ) one should not have a strong attitudinal barrier against receiving support; 4) one needs to perceive a need; and 5) one needs to be in a fairly stable situation. Furthermore, certain trigger events might help individuals to cross a particular threshold and/or might alter the weighing up of costs and benefits (Ibid.). Examples of such triggers include pregnancy, contacts with a stimulating peer and loss of a grant. Finally, van Oorschot (1998) draws attention to the factors on the side of the administration, by pointing out a list of potential factors. Hasenfeld's (2010) work on service delivery in human service organisations offers more conceptual and systematic insights. The quality and quantity of the services delivered by such organisations is affected by the working conditions. These conditions, according to Hasenfeld (2010), are affected by the caseload, the available resources (diagnostic tools and services), the (often conflicting) targets imposed, and the pressure of the reward system. In applying impersonal rules to real life cases, counsellors try to deal with these tensions by making use of discretion available to them (Lipsky, 1980). Hence, their decisions are partly affected by their own moral convictions, knowledge and experience and their sympathy for the client.

To conclude, both the non-take-up and the non-compliance literature identify potential factors affecting non-participation and these are situated at different levels: the service design level, the administrative-organisational level and the individual level. Figure 1 below represents this analytical framework visually. Note that the factors at the service design level were controlled for in our study.

\section{[figure 1]}




\section{Welfare-to-work in Belgium/Flanders}

While steps towards activation were in the early 1990s (e.g. the OCMW 'integration contract for young people' in 1993), the real breakthrough of the activation discourse in Belgium took place in 1999 when the first 'purple-green' government took office and proclaimed the transformation of a passive to an active welfare state as one of its main goals (Seynaeve et al., 2003). This transformation process involved the double individualisation strategy referred to above, particularly in Flanders. In order to reinforce the individual's responsibility for his/her reintegration into the labour market, the unemployment insurance scheme was revised in 2004. Under the revised scheme, the National Employment Office (RVA) - which decides on an unemployed individual eligibility for benefits - and the regional employment service (VDAB in Flanders) - which is in charge of guidance and training - jointly monitor the job search efforts of benefit claimants. RVA invites young benefit recipients who have been on benefits for 15 months to an interview. If it is found that the individual has failed to make sufficient efforts to find a job, an 'agreement' is drawn up specifying actions to be undertaken in the coming months. At a second negative interview $\left(19^{\text {th }}\right.$ month), stricter terms are imposed and a limited penalty is meted out. A third negative interview $\left(23^{\text {rd }}\right.$ month) results in the permanent suspension of benefits. It is important to keep in mind that the authority of the RVA is not limited to those presently receiving unemployment benefits but includes those who might be eligible in the future, as the RVA can postpone payment of the so-called waiting period allowance for school leavers (cf. above) or lower the amount.

While RVA reviews job search efforts at particular moments in time, it is the task of the four regional PESs to monitor these efforts permanently. More specifically, the Flemish VDAB is obliged to inform RVA when a young benefit claimant 1) fails to keep an appointment, 2) refuses a suitable job offer, 3) discontinues training due to lack of discipline, 4) fails to stick to the job coaching contract, and 5) refuses to sign a job coaching contract. 
This referral from the regional PES (VDAB) to RVA, also called 'file transmission', is typical of the Belgian activation policy.

As mentioned above, a second process of individualisation in the labour market policy took place simultaneously. More precisely, the Flemish government and VDAB established a new full coverage model (comprehensive approach or 'sluitende aanpak') for young people, i.e. the Youth Work Plan in September 2007. This YWP involves an integrated approach to activation with a strong focus on 'work first', an invitation extended to younger unemployed persons after the first months of unemployment, and extra support for those who are less selfreliant.

The so-called 'counsellors' of VDAB who execute this activation approach have mixed educational backgrounds and work experience. In Flanders, the bachelor or master study prepare students for social work in general rather than for a particular job. Moreover, a social work degree is an advantage though not a requirement to step into the job. Hence, applying Jewell's (2007) types of welfare workers we consider the Flemish counsellors to be closest to the conservative welfare state type (like Germany): counsellors have diverse educational backgrounds and their discretion is limited by regulatory complexity. This is in contrast to the social democratic approach in Scandinavia where counsellors are rather considered as professionals with a more substantial degree of discretion.

While the YWP allowed the VDAB to score high overall on the EU employment guideline regarding the 'comprehensive approach' (which requires that each young unemployed individual receives 'a new start' within 6 months), the Flemish government (2007) raised the concern that a vast group of young unemployed people - especially in the bigger cities appears to remain out of the VDAB's reach. To overcome these limits of activation, VDAB launched a range of pilots in 2008 to find the young non-participating unemployed in the city and to offer them more appropriate services. Drawing on an analysis of these pilots, the 
remainder of this article addresses the following key questions 1) who are these young unemployed people who not/no longer use the VDAB services?; 2) is their non-use a matter of non-compliance, non-take-up or both?; and 3) do these youngsters participate in the pilots, and why (not)?

\section{A Study of Flemish Pilots for Hard-to-reach Youngsters}

At the end of 2008 and the beginning of 2009, VDAB launched nine pilots for 'the young hard-to-reach unemployed' (18-25 years old) ${ }^{2}$ in eight Flemish cities ${ }^{3}$. VDAB defined the group more precisely as follows: on the one hand, the pilots are targeted at those who are 'not reachable (as they did not register), or have not (yet) been reached by VDAB'; on the other hand, the pilots target those who are 'occasionally but not systematically reached by VDAB making it is impossible to achieve a positive outcome'.

In seven of the eight cities, VDAB collaborates with so-called 'coaches' of local private nonprofit social work partner familiar with the group of non-participating young people - in the eight city, the coach is appointed by the city administration. In each pilot, the task of the coach is to 1) reach out to the target group by searching them proactively in the city, and 2) support them in their (re)insertion in the labour market. The payment of the partners was input-based (rather than result-based) i.e. on the basis of the efforts made to find 30 unemployed young people in the target group and to help them reinsert into the labour market. The partners were free to decide on the means of achieving these objectives, but VDAB imposed a number of minimal requirements.

To address the research questions, both quantitative and qualitative data were collected and analysed between July 2009 and February 2010. Two sources of quantitative data on the pilot participants were used: 1) the administrative client data of the PES and 2) a newly developed survey on the youngsters' characteristics and the individual job coaching process, to be completed by the coaches in the pilots. The fact that the survey is filled out by the coaches 
raises the concern that negative results might be under-reported. To reduce this risk, the researchers paid one or more visits to each site to conduct interviews with the coaches, the participants, the pilot partners and the VDAB staff members responsible for the pilots. The quantitative data were analysed using descriptives and cross-tabulations.

The qualitative data consisted of policy documents and a wide range of face-to-face and telephone interviews with stakeholders. Semi-structured face-to-face interviews were conducted with the seven VDAB staff members responsible for the pilots and the twelve coaches involved in the pilots. In addition, two VDAB counsellors and five staff members working for the various partner organisations ${ }^{4}$ of the pilot projects were interviewed by telephone.

Open interviews were conducted with the unemployed participants in the pilots. The interviewers did not make use of a pre-structured questionnaire, but used a topic sheet listing possible topics for discussion (the PES, the coach, income, work, family and friends) and participants were free to alter the topic and the direction of the interview at any time. The main focus of these interviews was the experience of the young unemployed with the PES in contrast to their experience in the pilot. Other topics were touched upon to get an understanding of the youngsters' personal context.

The sample design was not aimed at a proportional representation of key demographic characteristics of pilot participants. Rather, the cases were selected to include all possible outcomes of the job coaching process in the sample. Possible outcomes are: refusal to participate in the pilot, withdrawal from the pilot, participation without obtaining any work experience, and participation including work experience during the pilot. Secondly, participants were selected to ensure equal representation of both men/women, younger/older, native/immigrant, lower/higher educated participants. 
The initial response rate was rather low, as only 24 out of $48(50 \%)$ invited participants turned up. Though, in cities where coaches had more contact with their participants and reminded them about the interview several times, the rate was considerably higher. The interviewed participants received a small reward, i.e. a five euro phone voucher. Other unemployed youngsters accidentally dropping in on the day of the interview were also included in the interviewee sample. Thus, a total of 33 interviews were conducted. A selection effect may have occurred, since the last nine interviewees were probably more willing or able to participate in the pilot. On the other hand, some invited interviewees were unable to attend it because they had a job interview on the same day or had found a job in the meantime. Comparison of the interviewees with the total group of participants on a few key characteristics confirms that the two groups are largely similar except that the interviewees included slightly more youngsters of European origin and youngsters with a work disability (Table 1). Finally, in addition to these 33 interviewees, three young unemployed persons who refused to participate in the pilot could be contacted by phone.

[Table 1] 


\section{Results}

\section{Who Are the Young Non-participants?}

One year after the launch of the nine pilots, some 270 young unemployed persons had decided to participate. Many more young unemployed people were contacted by the coaches, but these either did not fit into the target group or refused to participate.

As Table 1 shows, the group of participants differed from the general unemployed population in Flanders in the same year. On average, the participants faced more obstacles to employment as they were lower educated, had been unemployed for a longer period and more often had a work disability. The pilot sample also contained at least twice as many youngsters of non-European origin than the total population. The fact that these youngsters tend to be lower educated and that they did not all master Dutch might explain their overrepresentation. Moreover, there is a gender bias in that men are overrepresented in the pilots. In the interviews the coaches identified several plausible hypotheses. Either fewer girls withdraw from the PES because of their sense of duty and their higher capacity to deal with the PES, or girls are less visible as compared to boys for they hang about less and exhibit fewer violent behaviour. Besides, it was said that in some domestic environment girls are not supposed to be in gainful employment.

The survey among the coaches indicated that only $17 \%$ of the participants were able to search for a job independently when they joined the pilot. The pilot participants not only had work-related barriers to employment: as the survey data indicate, the coaches had to help at least $80 \%$ of the participants with non-work-related obstacles in the following fields: administrative issues, finance, housing, the law, care commitments, health and language skills. Finally, the data confirm that the participants indeed did not/no longer use the services of the VDAB, although they were not completely unable to reach them. Few participants had never paid a single visit to the VDAB, while the majority had only failed to keep 
appointments later on. Half of the participants were referred to the RVA at least once for not showing up.

Why Do the Young Unemployed Not Make Use of the VDAB's Services?

As mentioned above, non-participation, can be interpreted as two different reactions to the activation policy, namely as a form of non-take-up of one's rights or as a form of noncompliance with one's obligations. The empirical evidence of this study points in both directions.

Starting with the issue of non-take-up, the survey results and interviews indicate that the pilot participants indeed had faced certain barriers in making use of the VDAB's services. A first barrier is the need to be aware of the existence of the service. While most interviewees knew the VDAB by name, they did not always understand its role and tended to confuse the VDAB with other institutions such as the RVA, the Public Centre for Social Welfare, the trade union, or the health insurance fund.

Secondly, some interviewees did not perceive the need to make use of the VDAB's services, although, a trigger event (e.g. marriage, pregnancy, or being granted custody) sometimes changed their perception:

'Well, I was sitting at home for a long time, I did not feel like, I really did not feel like [working]. (...) I was spending time in other social environments and I got in touch with bad guys. They were not thinking about work. You let yourself be dragged along. And then, one day, it hit me and I said, this ain't right, this should be stopped.'

Thirdly, a small group of youngster is in an unstable situation, facing so many personal problems that they no longer see the wood for the trees. Hence, work is not their first concern. No evidence was found of an eligibility misperception or of a firm attitudinal barrier against receiving support. 
The participants not only have to overcome certain barriers, but they are also presumed to weigh up the costs and benefits involved. Indeed, one of the reasons why the youngsters are badly informed about the VDAB (and other institutions) has to do with the cost and effort needed to gather and process this information. As most youngsters are low educated and/or have language difficulties, this cost is higher. Furthermore, the social and psychological costs are found to be rather high. Some interviewees felt trapped by labels such as 'immigrant', 'disabled', etc. Others experience disrespect as the VDAB does not take their personal situation into account:

'For the VDAB, the most important thing is that you keep your appointments and that you make sure you have a job. Your private life is not of interest to them.'

Surprisingly few interviewees explicitly named personal issues as a reason for not making use of VDAB services. However, the interviews and the survey among the coaches suggest that the personal problems that formed an important obstacle to their participation in the pilots must also have played a role in their previous dealings with the VDAB services (cf. below). Opportunity costs also play a role. Yet, in contrast to what is often presumed, the time spent on engaging with the VDAB not only constitutes a lost 'opportunity' to hang out with friends, to game or to sleep. For young second or third generation immigrants it is also time which they cannot spend on interpreting and arranging administrative matters for the family and community members who do not speak Dutch. Finally, no evidence could be found that the pecuniary (e.g. transport) or administrative costs involved in engaging with the VDAB were too high.

Looking at the benefits side, some interviewees indicate that they were disappointed by the VDAB services after they had made use of them once or several times. For many, engaging with the VDAB appeared daunting because they did not have the necessary computer skills or did not sufficiently understand the language used in the communication. They expected more 
support and assistance from the VDAB counsellor in their job search process to be really able to benefit.

'Yes somebody walks around to help, but there were others who needed help too. (...) Most people knew how to work with a computer, but I didn't, not at all.'

On the other hand, some interviewees disengaged from the VDAB when they felt pushed too hard by the counsellor, for instance to accept a less attractive job. Finally, some interviewees were disappointed as they had overestimated the potential benefits. They had expected the VDAB to give them a job immediately, as if it were a 'job distributor'.

The barriers preventing take-up should not only be looked for at the individual participant level. The interviews with the different stakeholders indicate that there are also problems at the administrative level. First and foremost, VDAB's counsellors have a very high caseload, which means they are not always able to: 1 ) invest extra time in assisting youngsters who need more support; 2) investigate each client's personal circumstances; and 3) allow some flexibility with regard to appointments. However, the interviews suggest that the latter two issues might partly be the result of the counsellors' moral convictions, education and training, and/or the guidelines provided. Another factor that hampers dealing with personal circumstances is the privacy law, which is implemented quite strictly by the VDAB. Finally, there is no evidence of a negative impact of a reward system for the counsellors.

Let us now look at this disengagement from the VDAB from another perspective, i.e. not as under-consumption of rights but as an act of non-compliance. In other words, do the youngsters deliberately disengage from the VDAB? Firstly, the high likelihood that noncompliance is detected does not seem to have discouraged the youngsters. No less than half of the participants had their file transferred to the RVA at least once, because they had failed to keep an appointment without a valid reason and had ignored the warning letter. According to the interviewees, they either did not receive this letter, found it too late, or did not understand 
it. Neither did they realise that their attendance was mandatory. This confirms Van Hemel et al.'s (2009) finding that young unemployed people are badly informed about their rights and obligations. This lack of knowledge among participants also undermines the deterrent effect of the penalty, as some interviewees were not aware of the existence of a financial penalty for not making use of VDAB services, while others underestimated the level of the sanction. This is especially the case for those not yet eligible for the waiting period allowance as they wrongly believe they cannot be sanctioned proactively.

Some persons, however, deliberately refused to participate, as was the case for instance for the interviewee quoted above who was hanging out with non-supportive friends. For these participants, the (non-) market opportunity cost of making use of the service is too high. Those youngsters who prefer to remain inactive can often rely on their family or a partner for their financial support. Others were employed in the 'black' (e.g. construction or catering) or illegal (e.g. drugs or prostitution) labour market. For them, leaving work to attend an appointment at the VDAB could be costly, as they might lose their job or be caught.

Finally, the phenomenon that Dean termed the 'self-assertion strategy' appeared in certain interviews. For these interviewees, the negative experiences with the VDAB (stigma, pressure, complex services) which affected their self-respect and self-confidence were a trigger for non-compliance.

Do the Youngsters Participate in the Pilots, and Why (Not)?

While an extensive discussion of the pilots is out of the scope of this article, it is relevant to have a quick look at what results they achieve and how they do so. The coaches in the pilot initiatives proved more successful than VDAB in reaching out to the youngsters. The main reasons for this success are related to the main characteristics of the approach applied by the coaches. Their 'integrated guidance approach' originated in the world of the local community 
and non-profit organisations in the second half of the 1980s (van den Berg and van der Veer, 1992; Leroy, 1992).

To enable the youngsters to overcome the individual barriers to take-up, the coaches 1) repeatedly reached out to them in public spaces; 2) encouraged their participation in deciding on the pace and the design of the counselling; and 3) identified and tackled their non-work related problems first. At the organisational level, in turn, the approach provided better working conditions i.e. a lower caseload (+- 30) and more flexibility. Moreover, thanks to their networks with diverse local public and private initiatives, the coaches had more resources at hand to combat both the work and the non-work related problems. Finally, youngsters were exempted from VDAB and RVA monitoring - as long as there were no indications of them abusing the system.

Nevertheless, the success of the pilots is not absolute. Despite the efforts of the coaches, $30,7 \%$ of the participants often did not keep an appointment; $10,4 \%$ suddenly stopped turning up; and 2,2\% never turned up after subscription. According to the responses of the coaches in the survey, thirty five youngsters faced behavioural and motivational problems while more than double of them faced (a combination) of e.g. debts, psychological problems, care task, judicial problems, drug related problems, relational problems and homelessness. About four participants disappeared as they moved - often in the hope to build up a new life elsewhere. Still others were found to have had a though childhood and/or youth and therefore have a long way to go when it comes to trusting institutions. At least three participants chose to stay in the black or illegal economy. Finally, three participants quit because they feared that they disappointed their coach. 


\section{Conclusions and Discussion}

The answer to the central question - should non-participation be attributed to non-compliance and/or to non-take-up? - is straightforward: in order to fully grasp the problem of nonparticipation in the PES, the theoretical insights into non-compliance and non-take-up should be combined. Indeed, some evidence was found for the dominant assumption that certain youngsters deliberately do not comply with their obligations. The opportunity costs (leisure; work in the black or illegal market) are considered too high while the penalty costs are underestimated (or unknown). However, the majority of the young NEETs under-consume their rights to activation due to diverse obstacles both at the individual and the organisational level. At the individual level, the following assumptions proposed by non-take-up theory were confirmed. A number of thresholds need to be crossed, i.e. unemployed people need to 1) be sufficiently aware of the existence of the services, 2) perceive a need for making use of these services, and 3) be in a stable situation. Subsequently, unemployed youngsters will continue to engage with the PES on the condition that they 1) have the necessary skills to make use of the services, and 2) perceive these services as providing tangible benefits. Factors at the organisational level affect this second set of conditions. More specifically, the high caseload of VDAB's counsellors as well as the VDAB self-help policy make the service difficult to access for those with limited coping skills. Clearly, the individual and organisational barriers are two sides of the same coin: if the PES were aware of and responsive to the individual obstacles of the youngsters, no organisational barriers would be there to overcome.

This brings us back to the three dilemmas in welfare work (autonomy-control, responsiveness-standardisation and supply-demand). The results indicate that achieving full coverage and providing tailored service delivery are not mutually exclusive goals. Instead, tailored service delivery is a prerequisite for achieving full coverage. This requires more autonomy for the counsellors and increased involvement of the participants in the design of 
the activation trajectory. The alternative approach taken in the pilots, i.e. 'integrated guidance' provides several keys which may be transferred to the PES under certain conditions. First, increased diversification of service delivery would enable the PES to concentrate resources on those who are most in need. This requires new screening tools that allow for a broad rather than a narrow assessment of the employability of unemployed individuals. That is to say, from a focus on skills and competences towards a holistic approach that includes all possible obstacles and strengths to sustainable employment. This would facilitate timely referral to the most appropriate service stream. Moreover, the range of services needs to be broadened so that the non-work related problems (e.g. psychological, relational, financial, legal, medical, drug related problems) can be tackled as well. To tackle these diverse problems in a coherent manner, multi-professional networks should be set up in collaboration with local social welfare organisations. To prevent the youngsters from falling through gaps between these institutions, one counsellor should act as a pivotal figure. Secondly, the existing monitoring and sanction regime needs to be questioned. Clearly, this regime has missed its goal since increased surveillance was unable to dissuade youngsters from non-participation. They were unaware of possible sanctions, underestimated future losses, or were indifferent due to the complexity of their problems. To avoid counterproductive effects, a 'tolerance period' should be introduced for those youngsters who need to overcome severe obstacles before reintegrating into the labour market. This would create the right climate for building a basis of trust between the youngster and the counsellor and would introduce some stability in the life of the youngsters. Just as in the experiments, monitoring and sanctions can still be imposed if there are signs that the system is being abused. Finally, young people should be better informed about their rights and obligations.

What could not be tested in this study is the role of the educational background of counsellors. It might be the case that PES counsellors with a social work background are 
better able to apply the integrated guidance approach of the coaches - of whom a large majority has this background. Though, as Jewell (2007) shows for welfare caseworkers in the US, Germany and Sweden, education is only one of many factors (such as those identified above: the available screening tools, the workload and strictness of rules) affecting the counsellor's behaviour. In any case, our study supports the finding in previous studies (see van Berkel \& van der Aa (2012) that activation work should be a professional rather than an administrative task. Hence the PES system should be reformed as aforementioned so as to increase the discretionary room of its counsellors to make professional judgments.

Yet these measures may not fully solve the problem. Despite the adoption of an integrated guidance approach combined with a tolerance period, the pilots also failed to (permanently) reach out to some youngsters. Hence, further research would need to examine whether these 'hard-core' non-participants are conscious non-compliers who refuse intervention of authorities or institutions linked to these authorities based on a religious or secular, philosophical conviction (see Dean, 2003); or non-take-uppers who have even more serious barriers to overcome. Nevertheless, the findings presented here indicate that a flexible though committal approach of reaching out to, guiding, involving and encouraging young people, is an important key to overcoming these limits of activation. 


\section{Acknowledgements}

This article is based on a scientific study by order of the Flemish public employment service (VDAB), entitled "Inappropriate questions or an inappropriate service? Final report of the evaluation study 'Pilots for the hard to reach in the framework of the Youth Work Plan"' (in Dutch) by Van Parys, L. \& Struyven, L. (2010), published by HIVA-KU Leuven, Leuven. The authors are grateful to their colleagues Greet Van Dooren and Kobe Van Itterbeeck who worked on the project as interviewers, and to the VDAB staff, the participants, the coaches and their partners who assisted the project. The first author's contribution was partly supported by a grant from the Research Foundation Flanders (FWO-Vlaanderen).

\section{Notes}

[1] In Belgium, school leavers are eligible for a so-called 'waiting period allowance' once they have been unemployed for nine months regardless of the number of days they have worked.

[2] An exception was made for two participants. They were 27 and 28 years old.

[3] The cities are Antwerpen, Eeklo, Genk, Gent, Hasselt, Kortrijk, Leuven, and Mechelen.

[4] Examples of partners are providers of skills and attitude training, the social assistance service (OCMW), a center for people with psychological problems, and a drug counselling center. 


\section{References}

Algemene Rekenkamer (2008) Aanpak harde kern jeugdwerklozen. Begeleiding van bij CWI geregistreerde jongeren, Sdu, 's Gravenhage.

Becker, G.S. \& Landes, W.M. (1974) Essays in the economics of crime and punishment, National bureau of economic research, New York.

Bentley, T. \& Gurumurthy, R. (1999) Destination Unknown: Engaging with the problems of marginalised youth, Demos, London.

Bonvin, J.M. (2008) 'Activation Policies, New Modes of Governance and the Issue of Responsibility', Social Policy and Society, vol. 7, no. 3, pp. 367-377.

Burgess, P.L. (1992) 'Compliance with Unemployment-Insurance Job-Search Regulations', Journal of Law and Economics, vol. 35, no. 2, pp. 371-396.

Chen, Y.W. (2011) 'Once a NEET always a NEET? Experiences of employment and unemployment among youth in a job training programme in Taiwan', International Journal of Social Welfare, vol. 20, pp. 33-42.

Dean, H. (2003) 'Re-conceptualising Welfare-To-Work for People with Multiple Problems and Needs', Journal of Social Policy, vol. 32, no.3, pp. 441-459.

Finn, D. (2003) 'The "Employment-first” Welfare State: Lessons from the New Deal for Young People', Social Policy \& Administration, vol. 37, no. 7, pp. 709-724.

Freedland, M. \& King, D. (2005) 'Client contractualism between the Employment Service and jobseekers in the United Kingdom', in Contractualism in Employment Services, eds E. Sol \& M. Westerveld, Kluwer, The Hague, pp. 119-39.

Furlong, A. (2006) 'Not a very NEET solution: representing problematic labour market transitions among early school-leavers', Work, Employment and Society, vol. 20, pp. 553-569. 
Gore, T. (2005) 'Extending Employability or Solving Employers' Recruitment Problems?

Demand-led Approaches as an Instrument of Labour Market Policy', Urban Studies, vol. 42, no. 2, pp. 341-353.

Handler, J.F .(2004) Social citizenship and workforce in the United States and Western Europe: the paradox of inclusion, Cambridge University Press, Cambridge.

Hasenfeld, Y. (ed) (2010) Human services as complex organizations, 2nd edn, Sage, Thousand Oaks.

Hernanz, V., Malherbet, F. \& Pellizzari, M. (2004) OECD Social, Employment and Migration Working Papers 17: Take-Up of Welfare Benefits in OECD Countries: A Review of the Evidence, OECD Publishing, Paris.

Hjörne, E., Juhila, K. \& van Nijnatten, C. (2010) 'Negotiating dilemmas in the practices of street-level welfare work', International Journal of Social Welfare, vol. 19, pp. 303309.

Jewell, C. J. (2007) 'Assessing Need in the United States, Germany, and Sweden: The Organization of Welfare Casework and the Potential for Responsiveness in the "Three Worlds", Law \& Policy, vol. 29, no. 3, pp. 380-406.

Lakey, J., Barnes, H. \& Parry, J. (2001) Getting a chance. Employment support for young people with multiple disadvantages, Joseph Rowntree Foundation, York.

Lawy, R. (2010), 'Young people's experiences of vocational education and training (VET)', Education + Training, vol. 52, no. 5, pp. $427-437$.

Leroy, F. (1992) De bestrijding van de langdurige werkloosheid in Vlaanderen. Naar een globaal actiemodel. Uitgeverij Focus, Vlezenbeek.

Lindsay, C. \& Mailand, M. (2004) 'Different routes, common directions? Activation policies for young people in Denmark and the UK', International Journal of Social Welfare, Vol. 13, pp. 195-207. 
Lipsky, M. (1980) Street-level bureaucracy: dilemmas of the individual in public services, Russell Sage Foundation, New York.

Malmberg-Heimonen, I. \& Vuori, J. (2005) ‘Activation or discouragement - the effect of enforced participation on the success of job-search training', European Journal of Social Work, vol. 8, no.4, pp. 451-467.

Marthinsen, E. \& Skjefstad, N. (2011) 'Recognition as a virtue in social work practice', European Journal of Social Work, vol. 14, no. 2, pp. 195-212.

Minas, R. (2005) 'Sifting the wheat from the chaff - the organization of telephone intake and the selection of social assistance inquirers in Sweden', European Journal of Social Work, vol. 8, no.2, pp. 145-164.

Pascual, A. S. (2009), 'The battle of ideas in the European field: the combat to defeat unemployment and the struggle to give it a name', European Review of Labour and Research, vol. 15, no. 1, pp. 53-70.

Seynaeve, T., Hermans, K., Declercq, A. \& Lammertyn, F. (2003) Aan de rand van de actieve welvaartsstaat: een socio-biografisch onderzoek naar jongeren en OCMWhulpverlening, Academia Press, Gent.

van Berkel, R. (2007) 'Individualised activation services in the EU', in Making it personal. Individualising activation services in the EU, eds R. van Berkel \& B. Valkenburg, The Policy Press, Bristol, pp. 245-264.

van Berkel, R. \& Valkenburg, B. (eds) (2007) Making it personal. Individualising activation services in the EU, The Policy Press, Bristol.

van Berkel, R. \& van der Aa, P. (2012) 'Activation Work: Policy Programme Administration or Professional Service Provision?', Journal of Social Policy, vol. 41, no. 3, 493-510. 
van den Berg, H. \& van der Veer, C.G. (1992) 'The Myth of 'Unemployable' People: an evaluation of a new employment service for the 'hard core' unemployed', Journal of Social Policy, vol. 21, no. 2, pp. 177-210.

Van Hemel, L. \& Struyven, L. (2008) 'De harde kern van activering door de bril van de jongeren', Over.werk, no. 3-4, pp. 68-75.

Van Hemel, L., Darquenne, R., Struyven, L., Vanderborght, Y. \& Franssen, A. (2009) Een andere kijk op hardnekkige jeugdwerkloosheid: Aanbevelingen en succesfactoren bij de inschakeling van laaggeschoolde jongeren. Koning Boudewijnstichting, Brussel.

van Oorschot, W. (1991) 'Non-Take-Up of Social Security Benefits in Europe', Journal of European Social Policy, vol. 1, no. 1, pp. 15-30.

van Oorschot, W. (1998) 'Failing selectivity: on the extent and causes of non-take-up of social security benefits', in Empirical poverty research in a comparative perspective, ed H. J. Andress, Ashgate, Aldershot, pp. 101-132.

VDAB studiedienst (2009) Jaarverslag Arbeidsmarkt Vlaanderen 2009, VDAB, Brussel. 